Revista de

Contabilidade e

Organizações

www.rco.usp.br
DOI: http://dx.doi.org/10.11606/issn.1982-6486.rco.2018.144885
Journal of

Accounting and

Organizations

www.rco.usp.br

\title{
Divulgação de ativos biológicos e concentração acionária nas empresas brasileiras do agronegócio
}

\section{Biological assets disclosure and ownership concentration in Brazilian agribusiness firms}

Júlia Peres Tortolia; Paulo Alexandre da Silva Pires ${ }^{\mathrm{b}}$; Ducineli Régis Botelhoc; Ilírio José Rech ${ }^{\mathrm{d}}$

${ }^{a}$ Universidade de São Paulo

${ }^{b}$ Universidade Federal de Santa Catarina

${ }^{-}$Universidade de Brasilia

${ }^{d}$ Universidade Federal de Goiás

Palavras-chave

Divulgação.

Ativos Biológicos.

Concentração Acionária

\begin{abstract}
Resumo
O presente artigo analisou a relação entre as práticas de divulgação de ativos biológicos e a concentração acionária nas empresas do agronegócio brasileiro. Foram analisadas as demonstrações contábeis de 27 empresas de capital aberto, para o período de 2011 a 2015. As evidências indicam que o nível de divulgação de ativos biológicos é ainda modesto nestas empresas, e que a concentração acionária típica do setor não afeta o nível de divulgação desses ativos. Os resultados confirmam estudos anteriores em relação aos efeitos do porte e da representatividade dos ativos biológicos na atividade das empresas.
\end{abstract}

Keywords

Disclosure.

Biological Assets.

Ownership Concentration.
Informações do Artigo

Recebido: 29 de março de 2018

Aceito: 13 de dezembro de 2018

Publicado: 19 de dezembro de 2018

\begin{abstract}
We investigated the relationship between biological assets disclosure and ownership concentration in Brazilian agribusiness industry. We analyzed 27 financial reports by Brazilian agribusiness public companies, for the period 2011 to 2015. The evidences indicate that the level of biological assets disclosure is still modest and ownership concentration typical in agribusiness industry does not affect decisions regarding biological assets disclosure. The results corroborate with previous evidences, demonstrating that company size and biological assets representativeness influence companies' activity.
\end{abstract}

\section{Implicações práticas}

Analistas e reguladores devem estar atentos ao baixo nível de divulgação de ativos biológicos em empresas de capital aberto do agronegócio brasileiro. $\mathrm{O}$ nível de divulgação de ativos biológicos é maior para as empresas de maior porte e representatividade de ativos biológicos em suas atividades, o que é esperado. A concentração acionária tende a não influenciar o nível de divulgação para as empresas analisadas, podendo ser decorrente justamente da alta concentração de capital, generalizada no setor, o que impede maiores níveis de divulgação.

Copyright (C) 2018 FEA-RP/USP. Todos os direitos reservados

\section{INTRODUÇÃO}

A aplicação dos conceitos contábeis pode ser vista como uma forma de tornar visíveis os fenômenos abstratos e complexos aos diferentes usuários (Potter, 2005). Nesse sentido, a sua aplicação se torna ainda mais relevante em atividades complexas, como a agrícola, que se caracteriza como uma atividade incomum para muitos usuários das informações contábeis (Elad, 2004).

Autor Correspondente: Tel. (16) 33154746

E-mail: jptortoli@usp.br (J. P. Tortoli); paulo.alexandre.pires@hotmail.com (P. A. da S. Pires); ducineli@unb.br (D. R. Botelho ); ilirio.jose@gmail.com (I. J. Rech)

Universidade de São Paulo. Faculdade de Economia, Administração e Contabilidade de Ribeirão Preto. Avenida Bandeirantes, 3900 - Monte Alegre - Ribeirão Preto/SP - 14040-905, Brasil 
Embora a atividade agrícola seja uma das mais antigas e relevantes para a sociedade, só recentemente ela se tornou objeto de preocupação dos contadores e da própria contabilidade (Gonçalves \& Lopes, 2014; Fischer \& Marsh, 2013; Elad \& Herbohn, 2011; Elad, 2004). Dessa forma, o International Accounting Standards Board (IASB) editou a International Accounting Standard 41 - Agriculture (IAS 41) em 2001, especifica para os ativos biológicos. No Brasil, em 2009, foi lançada a norma CPC 29 - Ativo biológico e produto agrícola, seguindo o IAS 41. O normativo exige que as empresas façam o reconhecimento, mensuração e evidenciação da produção e transformação de seus ativos biológicos e de seus produtos agrícolas em suas demonstrações contábeis. Buscou-se, com isso, regular a divulgação de ativos biológicos no país, aumentando a utilidade das informações contábeis, visando mitigar potenciais conflitos de agência envolvendo tais ativos (Fischer \& Marsh, 2013; Oliveira \& Rech, 2012), sobretudo em relação ao uso dessas informações pelos investidores (Scott, 2009).

Os estudos anteriores apontam um grau incompleto de cumprimento do CPC 29 pelas empresas brasileiras (Talaska \& Oliveira, 2016; Theiss, Utizig, Varela \& Beuren, 2014; Carvalho, Paulo, Sales \& Ikuno, 2013; Holtz \& Almeida, 2013; Silva, Figueira, Pereira \& Ribeiro, 2013). Adicionalmente, evidências sugerem uma alta variação no nível de divulgação de ativos biológicos dentro de um único setor (Talaska \& Oliveira, 2016). Diversos fatores são apontados como capazes de influenciar as decisões de divulgação de ativos biológicos, entre eles, o porte da empresa, o setor, a representatividade dos ativos biológicos, a rentabilidade e o nível de governança corporativa vigente na empresa (Nogueira \& Pires, 2017; Macedo, Campagnoli \& Rover, 2015; Gonçalves \& Lopes, 2014). Outro potencial fator de influência é a concentração acionária. Evidências tanto no contexto internacional (Bao \& Lewellyn, 2017; Patel, Balic \& Bwakira, 2002) quanto nacional (Herculano \& Moura, 2015) sugerem que os controladores podem se beneficiar do controle privado, afetando a qualidade dos relatórios reportados.

Em contextos de concentração acionária, um menor nível de divulgação contábil protegeria os interesses dos acionistas controladores (Herculano \& Moura, 2015), devido à significativa influência que eles possuem sobre a preparação das informações contábeis (Bao \& Lewellyn, 2017). Como exemplo, Gonçalves e Lopes (2014) analisaram a divulgação de ativos biológicos de 181 firmas listadas ao redor do mundo, para o ano de 2011, e demonstraram que a divulgação mandatória tende a ser influenciada pela representatividade dos ativos biológicos, porte da empresa e a concentração de capital.

Os mercados emergentes, como o Brasil, têm sido caracterizados pela elevada concentração acionária (Bao \& Lewellyn, 2017; Lopes \& Walker, 2008; La Porta, Lopez-de-Silanes \& Shleifer, 1998). Essa característica cria um ambiente favorável ao surgimento de conflitos de interesses entre os acionistas controladores e não controladores (Bao \& Lewellyn, 2017; Marques, Guimarães \& Peixoto, 2015; Caixe \& Krauter, 2013; Silveira, Barros, Silveira \& Famá, 2004; Dutra \& Saito, 2002; Claessens, Djankov, Fan \& Lang, 2002). A concentração acionária pode ser caracterizada pela presença de um grupo familiar ou um único indivíduo com poder de influência (Bao \& Lewellyn, 2017). Essa característica se confirma nas companhias do agronegócio brasileiro, nas quais, a maioria é controlada por famílias ou é originária de empresas familiares, como a JBS Brasil Foods, Fibria e São Martinho.

O presente artigo analisa a influência da concentração acionária no nível de divulgação de ativos biológicos para o setor do agronegócio brasileiro. Foram analisadas 27 empresas listadas na Bolsa de valores brasileira (B3), de 2011 a 2015. O setor do agronegócio é hoje responsável por cerca de $23 \%$ do Produto Interno Bruto (PIB) brasileiro, conforme demonstrado pela Confederação da Agricultura e Pecuária do Brasil (CNA, 2016). Os resultados demonstram que a simples presença de acionistas controladores no contexto da geração das demonstrações contábeis parece não afetar as decisões de divulgação de ativos biológicos no agronegócio brasileiro. Isso pode ser decorrente justamente da alta concentração de capital generalizada no setor, a qual impede maiores níveis de divulgação. Evidências adicionais sugerem fatores explicativos nessas decisões, como o porte da empresa e a representatividade dos ativos biológicos, corroborando com estudos anteriores.

Por fim, a análise das Notas Explicativas mostra que o grau de divulgação de ativos biológicos, em relação aos requisitos obrigatórios do CPC 29/IAS 41, é ainda modesto, apesar da curva de aprendizado da adoção dos padrões internacionais no Brasil (Talaska \& Oliveira, 2016; Theiss et al., 2014; Carvalho et al., 2013; Holtz \& Almeida, 2013; Silva et al., 2013). Espera-se, portanto, contribuir para a prática contábil, ao sinalizar a necessidade de maior atendimento às demandas informacionais dos usuários das demonstrações financeiras. 


\section{LITERATURA ANTERIOR}

A literatura contábil, ao discutir a assimetria informacional e o papel da contabilidade como fator redutor dessa anomalia, percebe a empresa como um conjunto de contratos (Scott, 2009; Sunder, 1997; Watts \& Zimmerman, 1986). Em um ambiente caracterizado pelo conflito de agência, a premissa central é que, com a separação de controle e propriedade, os recursos da empresa não são alocados eficientemente, pois os gestores não têm as mesmas motivações dos acionistas, em decorrência do desalinhamento de interesse entre os dois (Löfgren, Persson \& Weibull, 2002). No entanto, nos países em desenvolvimento, esse conflito surge, principalmente, pela presença de acionistas controladores, os quais buscam atingir benefícios próprios em detrimento dos acionistas não controladores (Bao \& Lewellyn, 2017; Marques et al., 2015; Caixe \& Krauter, 2013; Silveira et al., 2004; Dutra \& Saito, 2002; Claessens et al., 2002).

Consequentemente, a contabilidade é tida como fundamental para reduzir a assimetria informacional entre as partes (Sunder, 1997), por meio da transmissão da informação processada e evidenciada nas demonstrações financeiras (Sterling, 1967). A evidenciação contábil busca facilitar o entendimento dos eventos econômicos e financeiros na tomada de decisão, ao tornar mais evidente os fenômenos abstratos e complexos (Hendriksen \& Van Breda, 1999). Para isso, o Conceptual Framework for Financial Reporting (IFRS [International Financial Reporting Standards], 2010) aponta que os usuários devem estar razoavelmente preparados para receber e usar as informações contábeis com uma diligência razoável.

Uma ampla literatura tem buscado compreender as decisões de divulgação nas empresas, analisado potenciais fatores de influência nessas decisões, como a concentração acionária, os mecanismos de governança corporativa, o porte da empresa e a rentabilidade. A concentração acionária pode estar associada a menores níveis de divulgação e de transparência. Esta associação foi identificada por Patel et al. (2002) em 19 mercados emergentes. A concentração acionária também pode induzir ao gerenciamento de resultados, como mostrado por Bao e Lewellyn (2017) para 1200 empresas de 24 países emergentes. Adicionalmente, Aripin, Ho e Tower (2014) atribuiu aos mecanismos de governança corporativa a melhoria do nível médio de divulgação corporativa nas empresas da Malásia entre 2006 e 2009. No caso do Brasil, Herculano e Moura (2015) mostraram a relação da concentração com a divulgação contábil para 222 companhias de capital aberto brasileiras, no período de 2010 a 2012 .

A rentabilidade também pode estar associada às decisões de divulgação nas empresas. No entanto, Ashbaugh, Johnstone e Warfield (1999) e Haniffa e Cooke (2002) não oferecem um consenso. Ashbaugh et al. (1999) encontraram uma relação insignificante, enquanto que Haniffa e Cooke (2002) defendem que os gestores podem ser encorajados a divulgar mais informações, principalmente quando a rentabilidade é maior, expressando boa qualidade da gestão da empresa. Já a liquidez acionária tende a influenciar positivamente as empresas, principalmente em termos de valorização no mercado. Consequentemente, empresas mais líquidas tendem a aumentar a efetividade das informações divulgadas e a relação com os investidores (Amihud \& Mendlenson, 2008; Lang, Lins \& Maffett, 2012).

O porte da empresa também está relacionado à quantidade de informações divulgadas, como já apontado por Murcia, Fávero, Rover, Lima e Lima (2008), Avelino, Pinheiro e Lamounier (2012) e Nunes, Teixeira, Nossa e Galdi (2010). Essas evidências demonstraram que, de modo geral, o fator porte está relacionado à quantidade de informações divulgadas pelas empresas, principalmente, em decorrência de uma maior pressão política nas grandes empresas. Fatores macro institucionais também podem afetar as decisões de divulgação, como o nível de transparência no país. Nesse sentido, níveis de endividamento tendem a afetar a escolha sobre o nível de divulgação nas empresas brasileiras (Lanzana, 2004, Murcia et al., 2008; Nunes et al., 2010), principalmente por exigências do mercado e por questões reputacionais.

Em relação à divulgação de ativos biológicos, a análise de empresas de diversos países evidencia que a divulgação obrigatória é influenciada pela representatividade dos ativos biológicos, pelo porte, setor e estrutura de propriedade das empresas (Gonçalves e Lopes, 2014). Já para o contexto brasileiro, Silva et al. (2013) analisaram as informações fornecidas por empresas de capital aberto e fechado do agronegócio durante 2010, com foco nas exigências de divulgação do CPC 29/IAS 41. Os resultados do check-list mostraram que as empresas cumpriram parcialmente as exigências na primeira adoção desses padrões. Outros estudos também corroboraram nesse sentido (Talaska \& Oliveira, 2016; Theiss et al., 2014; Carvalho et al., 2013; Holtz \& Almeida, 2013). 
Macedo et al. (2015) analisaram 19 empresas de capital aberto em 2013, e confirmaram que setor, governança corporativa, porte, lucratividade e representatividade dos ativos biológicos na atividade da empresa influenciam na divulgação desses ativos. Nogueira e Pires (2017), além de confirmarem evidências anteriores do efeito do porte e representatividade dos ativos biológicos nas atividades das empresas, argumentam que a orientação técnica OCPC 07 - Evidenciação na Divulgação dos Relatórios Contábil-Financeiros de Propósito Geral teria trazido efeitos positivos no nível de divulgação.

\section{ASPECTOS METODOLÓGICOS}

A divulgação dos ativos biológicos foi normatizada pelo CPC 29/2009, em harmonia com as normas internacionais de contabilidade (IAS 41), que define ativo biológico como "um animal e/ou uma planta, vivos" e produto agrícola como "o produto derivado/colhido do ativo biológico". No contexto do agronegócio, os ativos biológicos são tidos como os fenômenos ou elementos biológicos presentes e resultantes do manejo de plantas e animais, transformados em produtos agrícolas, comercializados e consumidos seja por pessoas ou na cadeia produtiva de outras plantas e animais.

Destaca-se que o CPC 29 foi revisado em 2015, por meio da alteração da forma como as plantas portadoras são classificadas. As plantas portadoras referem-se às plantas utilizadas para a produção de produtos agrícolas, sendo cultivadas por mais de um período e que possuem uma possibilidade remota de serem vendidas, como, por exemplo, as seringueiras e videiras. Por meio da referida alteração, as plantas portadoras passam ao escopo das normas de ativo imobilizado (CPC 27/IAS 16).

Considerando que a adoção obrigatória se deu em 2016, as mudanças trazidas pela revisão do CPC 29 não foram comtempladas no presente estudo. A amostra da pesquisa compreende 27 empresas de capital aberto (listadas na B3) do agronegócio brasileiro para o período de 2011 a 2015. Buscou-se, com isso, uma expansão do período analisado após a adoção do CPC29/IAS 41 em relação aos estudos anteriores (Talaska \& Oliveira, 2016; Macedo et al., 2015; Gonçalves \& Lopes, 2014; Theiss et al., 2014; Carvalho et al., 2013; Silva et al., 2013).

Para a composição da amostra de pesquisa, foram consideradas apenas as empresas que exploraram ativos biológicos em pelo menos um ano do período analisado. Com isso, buscou-se garantir que a ausência de divulgação não fosse decorrente da ausência de necessidade de divulgação. Além disso, foram excluídas as empresas que apresentaram patrimônio líquido negativo, visando controlar possíveis efeitos no cálculo das variáveis de endividamento e rentabilidade.

Foi realizada a Análise de Conteúdo (Bardin, 2010) das Notas Explicativas nas divulgações financeiras das empresas, verificando os itens exigidos pelo CPC 29/IAS 41. O check-list dos itens exigidos pelo normativo contábil foi organizado em três etapas: (i) análise prévia, com a identificação e análise do CPC 29/IAS 41 no quesito de divulgação; (ii) exploração preliminar dos itens exigidos a serem analisados nas Notas Explicativas; (iii) tratamento dos resultados, inferência e classificação, caracterizado pela análise da informação divulgada pela empresa em relação ao exigido pelo normativo contábil. Os itens exigidos foram analisados e classificados em uma das três categorias: (i) divulgado; (ii) não divulgado; ou (iii) não aplicável. Adotou-se o mesmo peso para cada item requerido pelo normativo, seguindo Gray, Kouhy \& Lavers (1995).

Visando mitigar o grau de subjetividade inerente ao processo de análise de conteúdo, não se considerou a qualidade da informação divulgada, levando em conta apenas se a empresa divulgou (ou não) o item exigido no check-list. Exemplificando essa situação, as Notas Explicativas da Itausa S.A., em 2015, mencionaram que: "As florestas estão desoneradas de qualquer ônus ou garantias a terceiros, inclusive instituições financeiras. Além disso, não existem florestas cuja titularidade legal seja restrita" (Itausa, 2015, p. 64). Nesse caso, os itens $49 \mathrm{a}$ e $49 \mathrm{~b}$, exigidos pelo normativo contábil, foram considerados atendidos, visto que os itens requerem que a entidade divulgue restrições de titularidade legal e a quantidade de ativos biológicos oferecidos em garantias de exigibilidade.

Outro exemplo refere-se à depreciação. Esse item pode ser considerado como específico ao contexto de exploração dos ativos biológicos. Nesse caso, foi anotado "1" na categoria "não aplicável", se a empresa avaliou seus ativos biológicos pelo valor justo. Isso ocorre, pois, uma empresa possui obrigatoriedade de divulgação apenas se mensurar os ativos biológicos pelo custo histórico. 
Ressalta-se certa dificuldade em discernir se a divulgação é um caso de omissão da empresa ou de não aplicabilidade, apenas pela análise das Notas Explicativas. Esta dificuldade se dá sobretudo nos itens: (i) subvenções governamentais; (ii) ocorrência de eventos anormais; (iii) titularidade legal restrita e; (iv) estratégias e riscos financeiros na atividade agrícola. Tal dificuldade se dá pela própria falta de orientação da norma quanto à necessidade de explicitar quando não há aplicabilidade de determinadas exigências de divulgação.

O Índice de Evidenciação (DISC) para cada empresa em cada ano é a soma dos itens atendidos ("divulgados") dividido pelo total de itens aplicáveis (todos os itens, exceto "não aplicável"). Essa forma de cálculo não penaliza as empresas por itens nos quais elas não são obrigadas a divulgar. Por fim, o Índice de Evidenciação Binário (DISCbin) atribui 1 para empresas cujo Índice de Evidenciação no ano é superior à mediana da amostra naquele ano ou, zero se for menor.

A variável de interesse, Concentração Acionária (CONC), é a participação percentual cumulativa dos três maiores acionistas nas ações com direito a voto sobre o total de ações com direito a voto (Procianoy \& Schonorrenberger, 2004).

A relação esperada entre a concentração acionária e o índice de evidenciação binário é negativa, uma vez que o acionista controlador tende a se beneficiar de uma seleção adversa e proceder com divulgações seletivas. Assim, as empresas que possuem uma maior concentração acionária provavelmente irão divulgar níveis mais baixos de informações contábeis (Bao \& Lewellyn, 2017; Herculano \& Moura, 2015; Gonçalves \& Lopes, 2014; Patel et al., 2002).

O modelo (equação 1) inclui variáveis adicionais que tendem a afetar as decisões de divulgação de ativos biológicos, como a representatividade de ativos biológicos, o porte, o endividamento, a rentabilidade e a liquidez acionária. Foi utilizada a Regressão Logística, dado que a variável dependente é binária e verificou-se ausência de normalidade das variáveis independentes (Hair, Black, Babin, Anderson \& Tatham, 2009), por meio do teste Shapiro-Wilk (p-valor $<0,05)$.

$$
\operatorname{DISCbin}_{i, t}=\beta_{0}+\beta_{1} \operatorname{CONC}_{i, t}+\beta_{2} A B_{i, t}+\beta_{3} \text { Endiv }_{i, t}+\beta_{4} \text { Porte }_{i, t}+\beta_{5} \text { Rent }_{i, t}+\beta_{6} \text { LiqAC }_{i, t}+\mu_{i, t}
$$

Sendo, para cada empresa i no ano t,

DISCbin - Índice de Evidenciação Binário;

CONC - Concentração acionária;

AB - Representatividade dos Ativos Biológicos (ativo biológico de curto e longo prazo pelo ativo total);

Endiv - Endividamento (passivo total pelo patrimônio líquido);

Porte - Porte da empresa (logaritmo natural do ativo total);

Rent - Rentabilidade (lucro líquido pelo patrimônio líquido médio);

LiqAC - Liquidez acionária (abrange o total de dias e números de negócios da ação e o volume negociado, para 12 meses - calculado pelo Economatica $\left.{ }^{\circledR}\right)$.

Os dados da amostra são apresentados na Tabela 1. A amostra é composta por quatro segmentos de exploração dos ativos biológicos identificados nas Notas Explicativas: (i) Agricultura; (ii) Carne e Derivados; (iii) Madeira, Papel e Celulose e; (iv) Produção Sucroalcooleira. O segmento de Madeira, Papel e Celulose é o mais representativo (44\%). Nota-se que as empresas da amostra possuem cerca de $9 \%$ de ativos biológicos em relação ao total de seus ativos (representatividade dos ativos biológicos) para o período analisado. 
Tabela 1. Estatística descritiva

\begin{tabular}{rccccc}
\hline Variável & Obs. & Média & Desvio Padrão & Mín. & Máx. \\
\hline Índice de Evidenciação & 124 & 0,574 & 0,248 & 0,000 & 0,917 \\
Índice de Evidenciação Binário & 124 & 0,516 & 0,502 & 0,000 & 1,000 \\
Concentração Acionária & 134 & 0,694 & 0,197 & 0,310 & 1,000 \\
Representatividade dos Ativos Biológicos & 118 & 0,087 & 0,069 & 0,000 & 0,266 \\
Rentabilidade & 123 & 0,811 & 18,783 & $-94,440$ & 37,875 \\
Endividamento & 124 & 205,134 & 308,233 & 12,389 & 2379,27 \\
Porte & 134 & 15,224 & 1,801 & 11,815 & 19,713 \\
Liquidez Acionária & 135 & 0,330 & 0,565 & 0,000 & 3,121 \\
Segmento Madeira, Papel e Celulose & 135 & 0,444 & 0,499 & 0,000 & 1,000 \\
Segmento Carnes e Derivados & 135 & 0,222 & 0,417 & 0,000 & 1,000 \\
Segmento Agricultura & 135 & 0,185 & 0,390 & 0,000 & 1,000 \\
Segmento Produção Sucroalcooleira & 135 & 0,148 & 0,357 & 0,000 & 1,000 \\
\hline
\end{tabular}

Fonte: Elaborado pelos autores

A amostra analisada apresenta um nível de divulgação dos ativos biológicos mediano, o Índice de Evidenciação (58\% em média) mostra que metade dos itens aplicáveis é atendido em geral. Casos extremos de nenhuma divulgação, ou praticamente $90 \%$ dos itens aplicáveis estão presentes na amostra. O mesmo índice, em escala binária, classifica cerca de $51 \%$ das empresas acima da mediana da amostra.

Quando se analisa a falta de adesão completa aos requerimentos, nota-se que alguns itens não foram divulgados pelas empresas em todo o período analisado, como: (i) perdas irrecuperáveis; (ii) reversão de perdas irrecuperáveis e; (iii) divulgação de quaisquer circunstâncias de que o valor justo se torna mensurável confiavelmente. Esses achados corroboram com o estudo prévio de Silva et al. (2013). Dessa forma, destaca-se que, mesmo após um período de aprendizagem, essas características se mantêm, emergindo a necessidade de diretrizes futuras pelos órgãos normativos no que tange à divulgação das informações sobre ativos biológicos, principalmente em relação a itens de maior complexidade, de modo que as empresas possam fornecer informações úteis para auxiliar os usuários.

Além disso, a análise das notas explicativas mostrou que alguns itens sofreram alterações significativas no período analisado. O ganho ou a perda decorrente das mudanças ocorridas no valor contábil entre o início e o fim do período foi o item que apresentou maior divulgação pelas empresas, sendo que, praticamente a totalidade das empresas divulgou essa informação. No entanto, com o passar dos anos, esse item sofreu um decréscimo, embora ainda possua uma porcentagem alta de divulgação em relação aos demais. Esse decréscimo pode ser percebido em todos os segmentos, embora o de Carne e Derivados tenha se destacado por apresentar uma melhor divulgação.

Corroborando com o achado anterior, a divulgação das mudanças no valor contábil dos ativos biológicos entre o início e o fim do período foi apresentada de forma mais sintética no decorrer dos anos analisados. Adicionalmente, destaca-se os ganhos ou perdas decorrentes de eventos climáticos ou naturais, como surtos de virose, inundações, secas e geadas, são informações menos divulgadas pelas companhias, mas obtiveram um crescimento na taxa de divulgação com o passar dos anos. Grande parte desse crescimento é atribuído, principalmente, aos segmentos de Madeira, Papel e Celulose e de Agricultura.

A Tabela 1 retrata que a concentração acionária varia de 30\% a 100\% na amostra. Em média, os 3 maiores acionistas detêm cerca de $70 \%$ das ações com direito a voto nas empresas brasileiras do agronegócio, no período analisado. De acordo com evidências de Caixe e Krauter (2013), as empresas brasileiras possuem baixas taxas de alteração na composição acionária. Essa característica do mercado brasileiro tende a não estimular mudanças na divulgação de seus ativos biológicos, como pôde ser visto em várias Notas Explicativas, ilustradas pelo caso do grupo Itausa S.A., o qual divulgou o mesmo texto em todos os anos analisados.

O padrão da estrutura de concentração acionária se manteve com o passar dos anos (ver histogramas no Apêndice A), o que corrobora com os achados de Caixe e Krauter (2013). No ano de 2011 ainda é perceptível uma frequência maior de empresas com concentração entre $80 \%$ e $100 \%$. Com o passar dos anos, a concentração de capital dos três maiores acionistas reduziu para $60 \%$ ou mais. Isso sugere evidências de uma concentração generalizada no setor do agronegócio brasileiro. 
Destaca-se que a concentração varia com o setor (ver histogramas no Apêndice B). Os segmentos de maior concentração de capital são os de Madeira, Papel e Celulose e Produção Sucroalcooleira. O segmento que possui maior dispersão, relativamente, é o de Carne e Derivados, porém, a concentração de capital ainda é expressiva, com maior frequência de empresas nas concentrações superiores a $60 \%$.

\section{ANÁLISE DOS RESULTADOS}

A evidenciação dos ativos biológicos é apresentada na Tabela 2, destacando o comportamento do Índice de Evidenciação, para cada um dos segmentos de exploração de ativos biológicos.

Tabela 2. Evolução do Índice de Evidenciação

\begin{tabular}{rccccccc}
\hline & & & \multicolumn{5}{c}{ Índice de Evidenciação médio } \\
\cline { 4 - 8 } Segmento & $\mathbf{n}$ & $\mathbf{n}$ \% & $\begin{array}{c}\mathbf{2 0 1 1} \\
\mathbf{\%}\end{array}$ & $\begin{array}{c}\mathbf{2 0 1 2} \\
\mathbf{\%}\end{array}$ & $\begin{array}{c}\mathbf{2 0 1 3} \\
\mathbf{\%}\end{array}$ & $\begin{array}{c}\mathbf{2 0 1 4} \\
\mathbf{\%}\end{array}$ & $\begin{array}{c}\mathbf{2 0 1 5} \\
\mathbf{\%}\end{array}$ \\
\hline Madeira, Papel e Celulose & 12 & 44,44 & 63,74 & 64,89 & 62,63 & 59,17 & 66,70 \\
Agricultura & 5 & 18,52 & 57,59 & 58,75 & 42,00 & 45,44 & 60,57 \\
Carnes e Derivados & 6 & 22,22 & 43,68 & 46,03 & 51,71 & 53,57 & 49,07 \\
Produção Sucroalcooleira & 4 & 14,81 & 75,16 & 79,29 & 57,60 & 46,52 & 42,39 \\
\hline Total Geral & $\mathbf{2 7}$ & $\mathbf{1 0 0}$ & $\mathbf{5 9 , 0 6}$ & $\mathbf{6 1 , 5 7}$ & $\mathbf{5 5 , 2 2}$ & $\mathbf{5 3 , 2 8}$ & $\mathbf{5 7 , 7 0}$ \\
\hline
\end{tabular}

Fonte: Elaborado pelos autores

Nota: $\mathrm{n}$ - número de empresas por segmento.

A média anual da divulgação na Tabela 2 é relativamente estável no período analisado. O índice médio de divulgação por ano alcançou seu maior valor em $2012(0,61)$ e o menor em $2014(0,53)$. Essa variação indica que, em média, não há crescimento na curva de aprendizado, assim como não há uma maior evidenciação das informações recomendadas pela norma ao passar dos anos, como seria de esperar.

O segmento de Madeira, Papel e Celulose (com 44\% das empresas da amostra) tem a maior taxa de divulgação em 2015 (0,67). No entanto, observa-se picos de divulgação, como em Produção Sucroalcooleira nos anos de 2011 e 2012 e do setor de Madeira, Papel e Celulose nos anos de 2013, 2014 e 2015. O segmento de menor divulgação foi Agricultura em 2013 e de Carnes e Derivados em 2011 e 2012.

Considerando a segmentação setorial, a análise das notas explicativas demonstrou que as empresas sucroalcooleiras são as que possuem a menor divulgação de uma descrição dos ativos biológicos, exigida pelo item 41 da norma. Essa baixa evidenciação poderá gerar um prejuízo na compreensibilidade das divulgações contábeis dessas empresas, sobretudo, quando forem adotadas as alterações referentes às plantas portadoras, as quais estão presentes nessa atividade, por conta da existência de soqueiras da cana-de-açúcar.

Em relação ao segmento de Agricultura, observa-se a mais baixa divulgação da natureza das atividades em que cada grupo dos ativos biológicos está envolvido, assim como uma baixa divulgação do aumento de ativos biológicos por compras. Isso pode estar relacionado à própria especificidade do segmento, no qual esses ativos são cultivados desde o plantio ao invés de serem adquiridos. Ressalta-se que essas empresas, ao contrário dos demais segmentos, não divulgaram a existência de ativos biológicos dados em garantia ou com titularidade legal restrita em todos os anos.

O segmento de Carne e Derivados destacou-se por ter a melhor divulgação do ganho ou perda do ativo biológico e do produto agrícola, visto que, em quatros anos de análise, todas as empresas divulgaram esse item. Além disso, o item 54, exigido quando a entidade mensura ativos biológicos pelo custo, foi divulgado pela maioria das empresas de Carne e Derivados no período analisado. Isso pode ter ocorrido pela própria característica dos ativos biológicos, por exemplo, as aves, as quais possuem tempo de maturação menor e são avaliadas pelo custo.

Por fim, as empresas do segmento de Madeira, Papel e Celulose, embora tenham apresentado um crescimento no nível de divulgação de eventos climáticos ou naturais com o passar dos anos, ainda é o segmento que possui as mais baixas divulgações dessas informações, o que chama a atenção, considerando que os incêndios são relativamente frequentes nesse tipo de atividade. 
Destaca-se que algumas empresas da amostra apresentam pouca relação entre a sua atividade principal e o agronegócio, como Itausa (Investimentos), Randon (Automobilística) e Battistella (Varejo e atacado). No entanto, observa-se que essas empresas exploram ativos biológicos, seja diretamente, ou por meio de suas controladas, conforme evidenciado nas Notas Explicativas. Consequentemente, essas empresas são obrigadas a atender as exigências de divulgação do CPC 29/IAS 41.

A Itausa detém através de sua controlada, reservas florestais de eucalipto e de pinus, já a Randon afirma possuir áreas de reflorestamento avaliadas a valor justo. Finalmente, o grupo Battistella apresenta um braço florestal da Battistella Florestal SA. As duas últimas empresas citadas apresentaram informações insuficientes sobre ativos biológicos em seus relatórios financeiros. Além dessas, outras empresas como Wembley, Metisa e Biosev também divulgaram poucas informações de ativos biológicos.

A baixa divulgação observada (Tabela 2) sinaliza a importância de melhores práticas de divulgação dos ativos biológicos. O resultado é similar ao estudo de Holtz e Almeida (2013) que mostra a baixa divulgação para empresas brasileiras de 2010 e 2011. Outros estudos, como Talaska e Oliveira (2016), Theiss et al. (2014), Carvalho et al. (2013) e Silva et al. (2013) também demonstraram um nível de divulgação incompleto, mesmo com a exigência de informações obrigatórias pelo CPC 29/IAS 41. Figueira e Ribeiro (2016) complementam que, embora as empresas brasileiras tenham melhorado o nível de divulgação após o CPC 29, as informações podem não ser relevantes para os usuários, sendo apenas divulgadas por exigências legais.

Análises adicionais são apresentadas no Apêndice C. O Coeficiente de Correlação de Spearman evidenciou que existe uma correlação positiva entre a Representatividade dos Ativos Biológicos e a divulgação das empresas $(0,59)$. Ou seja, quanto mais o ativo biológico é representativo para a empresa mais ela realiza a sua divulgação. Esse resultado corrobora com os achados de Nogueira e Pires (2017), Macedo et al. (2015) e Gonçalves e Lopes (2014). Quanto aos segmentos, também houve coeficientes significativos, empresas de Madeira, Papel e Celulose $(0,26)$ e de Produção Sucroalcooleira $(0,29)$ apresentaram correlação positiva com o Índice de Evidenciação Binário. Por outro lado, empresas do segmento de Carnes e Derivados apresentaram correlação negativa $(-0,48)$.

Esse resultado pode ser explicado pelo tipo de ativo biológico que essas empresas exploram. Por exemplo, as florestas exploradas no segmento de Madeira, Papel e Celulose e, no segmento de Produção Sucroalcooleira, a cana-de-açúcar e as soqueiras. Esses ativos tendem a possuir um tempo de maturação maior, o que pode contribuir para que permaneçam evidenciados por um tempo maior nas demonstrações financeiras. Por outro lado, no segmento alimentício, ressalta-se, por exemplo, o caso das aves, as quais possuem o tempo de maturação curto, em alguns casos, é inferior a três meses. Porém, outros fatores podem ocasionar diferenças na divulgação entre os segmentos, os quais vão além do escopo da pesquisa. Consequentemente, pesquisas futuras poderiam analisar essas características.

O nível de concentração acionária e a divulgação de ativos biológicos foram testados pela Regressão Logística (Tabela 3). Por meio do teste GOF, o modelo é adequadamente especificado, indicando que as frequências esperadas são consistentes com as frequências observadas ( $\mathrm{p}$-valor $>0,05$ ). 
Tabela 3. Resultados da Regressão Logística

\begin{tabular}{|c|c|c|c|c|c|}
\hline \multirow{2}{*}{$\begin{array}{c}\text { Variável Dependente } \\
\text { Variáveis Independentes }\end{array}$} & \multicolumn{5}{|c|}{ Índice de Evidenciação Binário } \\
\hline & $\begin{array}{c}\text { Sinal } \\
\text { Esperado }\end{array}$ & Coef. & $\mathbf{z}$ & p-valor & $\begin{array}{c}\text { Nível de } \\
\text { Significância }\end{array}$ \\
\hline Concentração Acionária & $(-)$ & 1,054 & 0,62 & 0,537 & N.S. \\
\hline Representatividade dos Ativos Biológicos & $(+)$ & 23,756 & 3,95 & 0,000 & $* * *$ \\
\hline Rentabilidade & $(+/-)$ & $-0,012$ & $-0,64$ & 0,520 & N.S. \\
\hline Endividamento & $(+)$ & 0,000338 & 0,32 & 0,748 & N.S. \\
\hline Porte & $(+)$ & 0,882 & 2,83 & 0,005 & $* * *$ \\
\hline Liquidez Acionária & $(+)$ & $-1,194$ & $-1,33$ & 0,182 & N.S. \\
\hline Constante & N.A. & $-13,898$ & $-2,57$ & 0,010 & $* * *$ \\
\hline Controle de anos & \multicolumn{5}{|c|}{$\operatorname{sim}$} \\
\hline Controle de segmentos & \multicolumn{5}{|c|}{$\operatorname{sim}$} \\
\hline Pseudo $\mathrm{R}^{2}$ & \multicolumn{5}{|c|}{0,456} \\
\hline VIF médio & \multicolumn{5}{|c|}{2,14} \\
\hline Prob $>X^{2}$ & \multicolumn{5}{|c|}{$69,95 * * *$} \\
\hline Teste GOF & \multicolumn{5}{|c|}{0,153} \\
\hline Curva ROC & \multicolumn{5}{|c|}{0,916} \\
\hline $\mathrm{n}(\mathrm{obs})$ & \multicolumn{5}{|c|}{111} \\
\hline $\mathrm{n}$ (casos corretamente previstos) & \multicolumn{5}{|c|}{98} \\
\hline Sensitividade & \multicolumn{5}{|c|}{0,918} \\
\hline Especificidade & \multicolumn{5}{|c|}{0,84} \\
\hline
\end{tabular}

Fonte: Elaborado pelos autores

Nota: Nível de significância de 10\% (*). Nível de significância de 5\% (**). Nível de significância de 1\% (***). N.S. (não estatisticamente significante). N.A. (não aplicável).

Os testes mostram que a Concentração Acionária não tem efeito sobre as decisões de divulgação dos ativos biológicos no setor de agronegócio brasileiro. Essa evidência diverge dos achados de Bao e Lewellyn (2017), Herculano e Moura (2015) e Gonçalves e Lopes (2014), de que a concentração acionária reduz a qualidade da informação contábil. Outros fatores parecem explicar a divulgação de ativos biológicos para o agronegócio brasileiro. Os testes demonstram que a Representatividade dos Ativos Biológicos e o Porte da empresa são significativos, corroborando com evidências anteriores. Enquanto a representatividade pode ser explicada pelo maior volume de ativos biológicos que demandam maior cuidado com essas informações (Nogueira \& Pires, 2017; Macedo et al., 2015), o porte pode denotar que empresas maiores tendem a ser mais transparentes, devido aos custos políticos envolvidos. Deve-se notar que esse resultado está de acordo com os achados de Nogueira e Pires (2017), Macedo et al. (2015), Avelino et al. (2012), Murcia et al. (2008), Nunes et al. (2010) e Lanzana (2004).

A Rentabilidade não obteve significância estatística, corroborando com Ashbaugh et al. (1999), os quais encontraram evidências de uma relação insignificante entre o volume de informações divulgadas e a lucratividade das empresas. Da mesma forma, o endividamento também não obteve significância estatística, contrariando o argumento de que empresas com níveis mais altos de endividamento tendem a ser mais transparentes (Lanzana, 2004; Murcia et al., 2008; Nunes et al., 2010). Por fim, a falta de relação com a liquidez acionária também contraria o argumento de que as firmas mais líquidas tendem a possuir maior nível de divulgação de informações, como demonstrado por Amihud e Mendleson (2008) e Lang et al. (2012).

\subsection{Testes e análises adicionais}

Como teste de robustez, foram realizadas análises adicionais da relação entre a divulgação de ativos biológicos e a concentração acionária, com a utilização do Índice de Evidenciação em escala contínua. O Gráfico 1 demonstra que não existe uma relação estatisticamente significativa entre a divulgação de ativos biológicos e a concentração acionária $\left(\mathrm{R}^{2}\right.$ da linha de tendência $\left.=0,028\right)$. Os pontos ao redor da área do gráfico também não sugerem que existe uma relação aparente entre eles. 


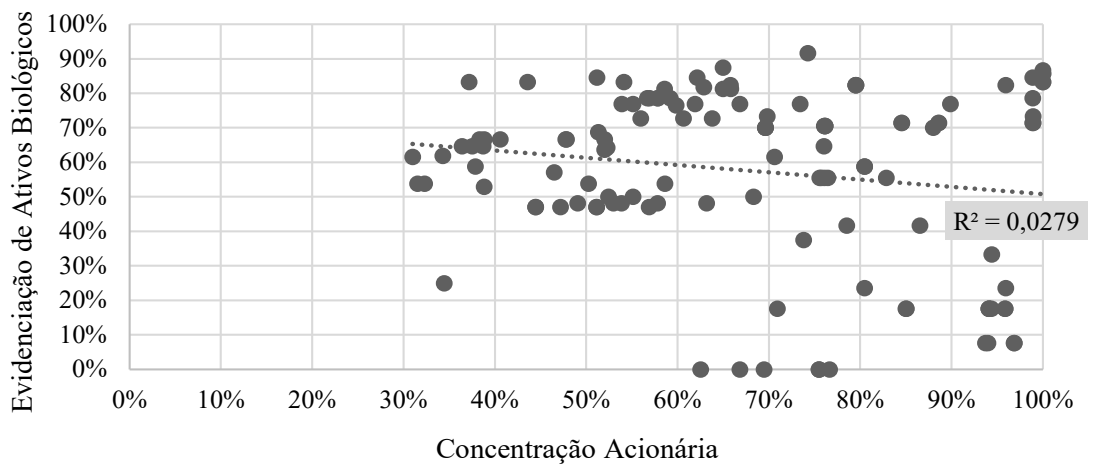

- Índice de cada empresa em um determinado período

Gráfico 1. Dispersão

Fonte: Elaborado pelos autores

Análises complementares estão elencadas no Apêndice D. Conforme demonstrado, os gráficos de dispersão anuais sugerem que não existe uma relação significativa entre a concentração acionária e a divulgação de ativos biológicos, corroborando com o gráfico 1. Ressalta-se que, no ano de 2014, o coeficiente foi mais significativo (em torno de 10\%), destacando um coeficiente negativo entre a divulgação dos ativos biológicos e a concentração acionária, ou seja, maiores níveis de concentração acionária sugerem níveis menores de divulgação. Além disso, o comportamento dos gráficos foi semelhante em cada um dos anos analisados, indicando um maior aglomerado de pontos a partir de $60 \%$ de concentração de capital.

A utilização de variável binária pode limitar as análises dos resultados dos modelos de regressão, uma vez que essa variável tende a não capturar variações relevantes nas informações de divulgação dos ativos biológicos. Assim, procedeu-se a o teste de dados em painel por efeitos aleatórios usando o Índice de Evidenciação em escala contínua. A estimação com dados em painel, Tabela 4, atende aos pressupostos de ausência de multicolinearidade $(\mathrm{VIF}$ médio $=1,73$ ) e ausência de heteroscedasticidade (teste de Breusch-Pagan/Cook-Weisberg p-valor $=0,542$ $>0,05)$. Além disso, o diagnóstico de dados em painel demonstra que é recomendável a utilização de efeitos aleatórios (teste de Hausman com p-valor $=0,102>0,05$ ). 
Tabela 4. Estimação de dados em painel por Efeitos Aleatórios

\begin{tabular}{|c|c|c|c|c|c|}
\hline \multicolumn{2}{|l|}{ Variável Dependente } & \multicolumn{3}{|c|}{ Índice de Evidenciação Binário } & \multirow[b]{2}{*}{$\begin{array}{c}\text { Nível de } \\
\text { Significância }\end{array}$} \\
\hline Variáveis Independentes & $\begin{array}{c}\text { Sinal } \\
\text { Esperado }\end{array}$ & Coef. & $\mathbf{z}$ & p-valor & \\
\hline Concentração Acionária & $(-)$ & $-0,198$ & $-1,32$ & 0,188 & N.S. \\
\hline Representatividade de Ativos Biológicos & $(+)$ & 0,836 & 1,92 & 0,054 & $* *$ \\
\hline Rentabilidade & $(+/-)$ & $-0,000$ & $-0,32$ & 0,750 & N.S. \\
\hline Endividamento & $(+)$ & $-0,000$ & $-0,13$ & 0,896 & N.S. \\
\hline Porte & $(+)$ & 0,051 & 2,21 & 0,027 & $* *$ \\
\hline Liquidez Acionária & $(+)$ & $-0,054$ & $-1,37$ & 0,172 & N.S. \\
\hline Constante & N.A. & 0,793 & $-0,11$ & 0,913 & N.S. \\
\hline Controle de Segmentos & \multicolumn{5}{|c|}{$\operatorname{sim}$} \\
\hline $\mathrm{R}^{2}$ total & \multicolumn{5}{|c|}{0,469} \\
\hline Prob. Chi2 & \multicolumn{5}{|c|}{$17,43 * *$} \\
\hline VIF médio & \multicolumn{5}{|c|}{2,34} \\
\hline $\mathrm{N}(\mathrm{obs})$ & \multicolumn{5}{|c|}{111} \\
\hline $\mathrm{N}$ (grupos) & \multicolumn{5}{|c|}{26} \\
\hline Teste de Heteroscedasticidade (p-valor) & \multicolumn{5}{|c|}{$0,37(0,542)$} \\
\hline Teste de Chow & \multicolumn{5}{|c|}{$10,71^{* * *}$} \\
\hline Teste de Breusch- Pagan/ Lagrangian & \multicolumn{5}{|c|}{$36,15^{* * *}$} \\
\hline Teste de Hausman (p-valor) & \multicolumn{5}{|c|}{$9,18(0,102)$} \\
\hline Modelo de Dados em Painel & \multicolumn{5}{|c|}{ Efeitos Aleatórios } \\
\hline
\end{tabular}

Fonte: Elaborado pelos autores

Nota: Nível de significância de 10\% (*). Nível de significância de 5\% (**). Nível de significância de 1\% (***). N.S. (não estatisticamente significante). N.A. (não aplicável).

Não há significância estatística entre o Índice de Evidenciação contínuo e a Concentração Acionária, corroborando com as estimações da Regressão Logística. Além disso, o modelo foi significativo (estat. Chi2 $<0,05$ ) e o poder explicativo está em torno de $47 \%$. Os resultados também demonstram que o índice de divulgação está relacionado com a Representatividade dos Ativos Biológicos e o Porte da empresa, conforme evidências anteriores. Embora a regressão logística possa limitar a análise devido à segregação em dois grupos (escala binária), os resultados dos dados do painel foram consistentes com estimativas anteriores, validando os achados e ampliando a possibilidade de aplicação.

\section{CONSIDERAÇÕES FINAIS}

Os resultados encontrados para a amostra de empresas brasileiras de Agronegócio listadas na bolsa de valores (B3), de 2011 a 2015, indicam que as decisões de divulgação de ativos biológicos parecem não estar associadas à concentração acionária. Esse efeito pode ser atribuído justamente à alta concentração de capital generalizada no setor.

Outros fatores se mostraram significativos nas decisões de divulgação dos ativos biológicos, como o porte e a representatividade dos ativos biológicos na atividade das empresas. Embora haja um número reduzido de empresas, destaca-se que as análises englobaram todas as empresas listadas brasileiras com informações disponíveis sobre ativos biológicos em pelo menos um dos anos do período analisado.

De forma mais detalhada, a análise das notas explicativas evidenciou que o grau de divulgação incompleto ainda persiste mesmo após um período de aprendizagem desde a adoção do CPC 29, corroborando com evidências anteriores (Talaska \& Oliveira, 2016; Theiss et al., 2014; Carvalho et al., 2013; Holtz \& Almeida, 2013; Silva et al., 2013). A divulgação apenas parcial identificada no agronegócio brasileiro, sobretudo nos 3 segmentos mais críticos (Agricultura, Carnes e Derivados e Produção Sucroalcooleira) suscita estudos mais detalhados para entender as razões desse nível de divulgação. 
Pesquisas futuras poderiam analisar outros fatores potenciais de influência nas práticas de divulgação, como: (i) atributos da governança corporativa, além dos níveis atribuídos pela B3; (ii) medidas gerais de qualidade da informação contábil; (iii) os efeitos da mudança das plantas portadoras ao escopo do CPC 27/IAS 16, como a potencial perda de comparabilidade histórica nas demonstrações financeiras; (iv) os potenciais efeitos da emissão do Disclosure Initiative - Principles of Disclosure (IASB, 2017) em relação ao compliance dos requisitos exigidos pelo CPC 29/IAS 41.

\section{REFERÊNCIAS}

Amihud, Y., \& Mendelson, H. (2008). Liquidity, the Value of the Firm, and Corporate Finance. Journal of Applied Corporate Finance, 20, 32-45. DOI: https://doi.org/10.1111/j.1745-6622.2012.00362.x

Aripin, N., Ho, P., \& Tower, G. (2014). The Masters' Control: How Ownership Structure Influences the Communication of Financial Ratios. Asian Journal of Business and Accounting, 7(2), 45-69

Ashbaugh, J., Johnstone, K.M., \& Warfield, T.D. (1999). Corporate Reporting on the Internet. Accounting Horizons, 13(3), 241-257. DOI: https://doi.org/10.2308/acch.1999.13.3.241

Avelino, B.C., Pinheiro, L.E.T., \& Lamounier, W.M. (2012). Evidenciação de ativos intangíveis: um estudo empírico em empresas abertas. Revista de Contabilidade e Organizações, 6(14), 22-45. DOI: https://doi. org/10.11606/rco.v6i14.45399

Bao, S.R., \& Lewellyn, K.B. (2017). Ownership structure and earnings management in emerging marketsan institutionalized agency perspective. International Business Review, 26(5), 828-838. DOI: https://doi. org/10.1016/j.ibusrev.2017.02.002

Bardin, L. (2010). Análise de Conteúdo. 4ed. Lisboa: Edições 70

Caixe, D.F., \& Krauter, E. (2013). A influência da estrutura de propriedade e controle sobre o valor de mercado corporativo no Brasil. Revista Contabilidade \& Finanças, 24(62), 142-163. DOI: https://doi.org/10.1590/ S1519-70772013000200005

Claessens, S., Djankov, S., Fan, J.P.H., \& Lang, L.H.P. (2002). Disentangling the incentive and entrenchment effects of large shareholdings. The Journal of Finance, 57(6), 2741-2771.

Carvalho, F. S., Paulo, E., Sales, I. C. H., \& Ikuno, L. M. (2013). Ativos biológicos: evidenciação das empresas participantes do Ibovespa.Custose@gronegócio on line, 9(3), 106-130.

Comitê de Pronunciamentos Contábeis. (2009). CPC 29 - Ativo Biológico e Produto Agrícola.

Confederação da Agricultura e Pecuária do Brasil - CNA. (2016). Agropecuária supera obstáculos e segue liderando a economia brasileira em 2016.

Dutra, M. G. L., \& Saito, R. (2002). Conselhos de administração: análise de sua composição em um conjunto de empresas abertas brasileiras. Revista de Administração Contemporânea, 6(2), 9-27. DOI: https://doi. org/10.1590/S1415-65552002000200003

Elad, C. (2004). Fair value accounting in the agricultural sector: some implications for international accounting harmonization. European Accounting Review, 13(4), 621-641. DOI: https://doi. org/10.1080/0963818042000216839

Elad, C., \& Herbohn, K. (2011). Implementing fair value accounting in the agricultural sector. Edinburgh: Institute of Chartered Accountants of Scotland.

Figueira, L. M., \& Ribeiro, M. S. (2016). Análise da evidenciação sobre a mensuração de ativos biológicos: antes e depois do CPC 29. Revista Contemporânea de Contabilidade, 12(26), 73-98. DOI: https://doi. org/10.5007/2175-8069.2015v12n26p73

Fischer, M., \& Marsh, T. (2013). Biological assets: financial recognition and reporting using us and international accounting guidance. Journal of Accounting \& Finance, 13(2), 57-74.

Gonçalves, R., \& Lopes, P. (2014). Firm-specific Determinants of Agricultural Financial Reporting. Procedia Social and Behavioral Sciences, 110, 470-481. DOI: https://doi.org/10.1016/j.sbspro.2013.12.891 
Gray, R., Kouhy, R., \& Lavers, S. (1995). Corporate social and environmental reporting: a review of the literature and a longitudinal study of UK disclosure. Accounting, Auditing \& Accountability Journal, 8(2), 47 - 77. DOI: https://doi.org/10.1108/09513579510146996

Hair, J.F., Black, W.C., Babin, B.J., Anderson, R.E., \& Tatham, R.L. (2009). Análise multivariada de dados. 6ed. Porto Alegre: Bookman

Haniffa, R., \& Cooke, T.E. (2002). Culture, corporate governance and disclosure in malaysian corporations. Abacus, 38(3), 317-349. DOI: https://doi.org/10.1111/1467-6281.00112

Hendriksen, E.S., \& Van Breda, M.F. (1999). Teoria da contabilidade. São Paulo: Atlas

Herculano, H.A., \& Moura, G. D. (2015). Informação contábil e concentração acionária: Análise sob a ótica da persistência e da oportunidade. Revista Ambiente Contábil, 7(2), 231- 247.

Holtz, L., \& Almeida, J. E. F. (2013). Estudo sobre a relevância e a divulgação dos ativos biológicos das empresas listadas na BM\&FBOVESPA. Sociedade, Contabilidade e Gestão, 8(2), 28-46.

International Accounting Standards Board. (2017). Disclosure Initiative-Principles of Disclosure.

International Financial Reporting Standards. (2010). Conceptual Framework for Financial Reporting.

International Financial Reporting Standards. (2010). IAS 16 - Property, Plant and Equipment.

International Financial Reporting Standards. (2010). IAS 41 - Agriculture.

Itausa. (2015). Demonstrações Financeiras Completas. Recuperado de: http://www.itausa.com.br/PT/ Documentos/6095_DCC_31122015.pdf

La Porta, R., Lopez-de-Silanes, F., \& Shleifer, A. (1999). Corporate ownership around the world. The Journal of Finance, 54(2), 471-517. DOI: https://doi.org/10.1111/0022-1082.00115

Lang, M., Lins, K.V., \& Maffett, M. (2012). Transparency, liquidity, and valuation: international evidence on when transparency matters most. Journal of Accounting Research, 50(3), 729-774. DOI: https://doi.org/10.1111/ j.1475-679X.2012.00442.x

Lanzana, A.P. (2004). Relação entre disclosure e governança corporativa das empresas brasileiras. (Dissertação de Mestrado, Programa de Pós-Graduação em Administração, Universidade de São Paulo).

Löfgren, K.G., Persson, T., \& Weibull, J.W. (2002). Markets with asymmetric information: The contributions of George Akerlof, Michael Spence and Joseph Stiglitz. The Scandinavian Journal of Economics, 104(2), $195-211$.

Lopes, A.B., \& Walker, M. (2008). Firm-Level incentives and the informativeness of accounting reports: an experiment in Brazil. Working Paper. DOI: https://doi.org/10.2139/ssrn.1095781

Macedo, V. M., Campagnoni, M., \& Rover, S. (2015). Ativos Biológicos nas Empresas Abertas no Brasil: Conformidade Com o CPC 29 e Associação com Características Empresariais. Sociedade, Contabilidade e Gestão, 10(3), 07-24.

Marques, T.A., Guimaraes, T.M., \& Peixoto, F. M. (2015). A concentração acionária no Brasil: análise dos impactos no desempenho, valor e risco das empresas. RAM, Rev. Adm. Mackenzie [online], 16(4), 100-133. DOI: http:// dx.doi.org/10.1590/1678-69712015/administracao.v16n4p100-133

Murcia, F.D., Fávero, L.P.L., Rover, S., Lima, G.A.S.F., \& Lima, I. (2008). 'Disclosure verde’ nas demonstrações contábeis: características da informação ambiental e possíveis explicações para a divulgação voluntária. Revista UnB Contábil, 11(1-2), 260-278.

Nogueira, D. R., \& Pires, P. A. S. (2017). Nível de Disclosure do CPC 29 Ativos Biológicos: Análise dos fatores determinantes nas empresas brasileiras. Contabilidade, Gestão e Governança, 20(1), 38-54. DOI: https://doi. org/10.21714/1984-3925_2017v20n1a3

Nunes, J.G., Teixeira, A.J.C., Nossa, V., \& Galdi, F.C. (2010). Análise das variáveis que influenciam a adesão das empresas ao índice BM\&F Bovespa de sustentabilidade empresarial. BASE - Revista de Administração e Contabilidade da Unisinos, 7(4), 328-340. DOI: https://doi.org/10.4013/base.2010.74.06

Oliveira, A.T., \& Rech, I. J. (2012). Conteúdo informativo da Contabilidade. In Contabilidade e Finanças no Brasil: estudos em homenagem ao professor Eliseu Martins. São Paulo, SP: Atlas 
Patel, S., Balic, A., \& Bwakira, L. (2002). Measuring transparency and disclosure at firm-level in emerging markets. Emerging Markets Review, 3(4), 325-337. DOI: https://doi.org/10.1016/S1566-0141(02)00040-7

Potter, B.N. (2005). Accounting as a social and institutional practice: perspectives to enrich our understanding of accounting change. Abacus, 41(3), 265-289. DOI: http://onlinelibrary.wiley.com/doi/10.1111/j.14676281.2005.00182.x/abstract

Procianoy, J., \& Schonorrenberger, A. A. (2004). Influência da estrutura de controle nas decisões de estrutura de capital das empresas brasileiras. Revista Brasileira de Economia, 58(1), 121-146. DOI: https://doi. org/10.1590/S0034-71402004000100006

Scott, W.R. (2009). Financial Accounting theory. 5th ed. USA: Pearson

Silva, R. L. M., Figueira, L. M., Pereira, L. T. O. A, \& Ribeiro, M. S. (2013). CPC 29: uma análise dos requisitos de divulgação entre empresa de capital aberto e fechado do setor de agronegócios. Sociedade, Contabilidade e Gestão, 8(1), 26-49.

Silveira, A.D.M., Barros, L.A.B.C., Silveira, H.P., \& Famá, R. (2004). Determinantes da concentração do direito de controle nas empresas abertas brasileiras. Trabalho apresentado no IV encontro Brasileiro de Finanças. Rio de Janeiro, RJ

Sterling, R. (1967). A statement of basic accounting theory. Journal of Accounting Research, 5(1), 95-112. DOI: https://doi.org/10.2307/2489988

Sunder, S. (1997). Theory of accounting and control. Ohio, USA: South -Western Publishing

Talaska,A., \& Oliveira, D. L. (2016). Nível de disclosure de ativos biológicos nas empresas listadas na bm\&fbovespa: análise pós-adoção do valor justo. Revista de Contabilidade do Mestrado em Ciências Contábeis da UERJ, 21(3), 22-39. DOI: https://doi.org/10.12979/22942

Theiss, V., Utizig, M. J. S., Varela, P. S., \& Beuren, I. V. (2014). Práticas de divulgação dos ativos biológicos pelas empresas listadas na BM\&FBOVESPA. ReCont, 5(3), 41-58.

Watts, R,L., \& Zimmerman, J.L.(1986). Positive accounting theory. USA: Prentice Hall

\section{Como citar este artigo}

Tortoli, J. P., Pires, P. A. da S.; Botelho, D. R.; \& Rech, I. J. (2018). Divulgação de Ativos Biológicos e Concentração Acionária nas Empresas Brasileiras do Agronegócio. Revista de Contabilidade $e$ Organizações, 12:e144885. DOI: http://dx.doi.org/10.11606/issn.1982-6486.rco.2018.144885 


\section{APÊNDICES}

\section{Apêndice A - Histogramas (por ano - em número de empresas)}

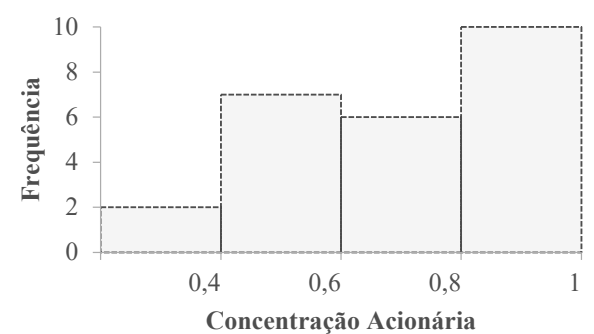

2011
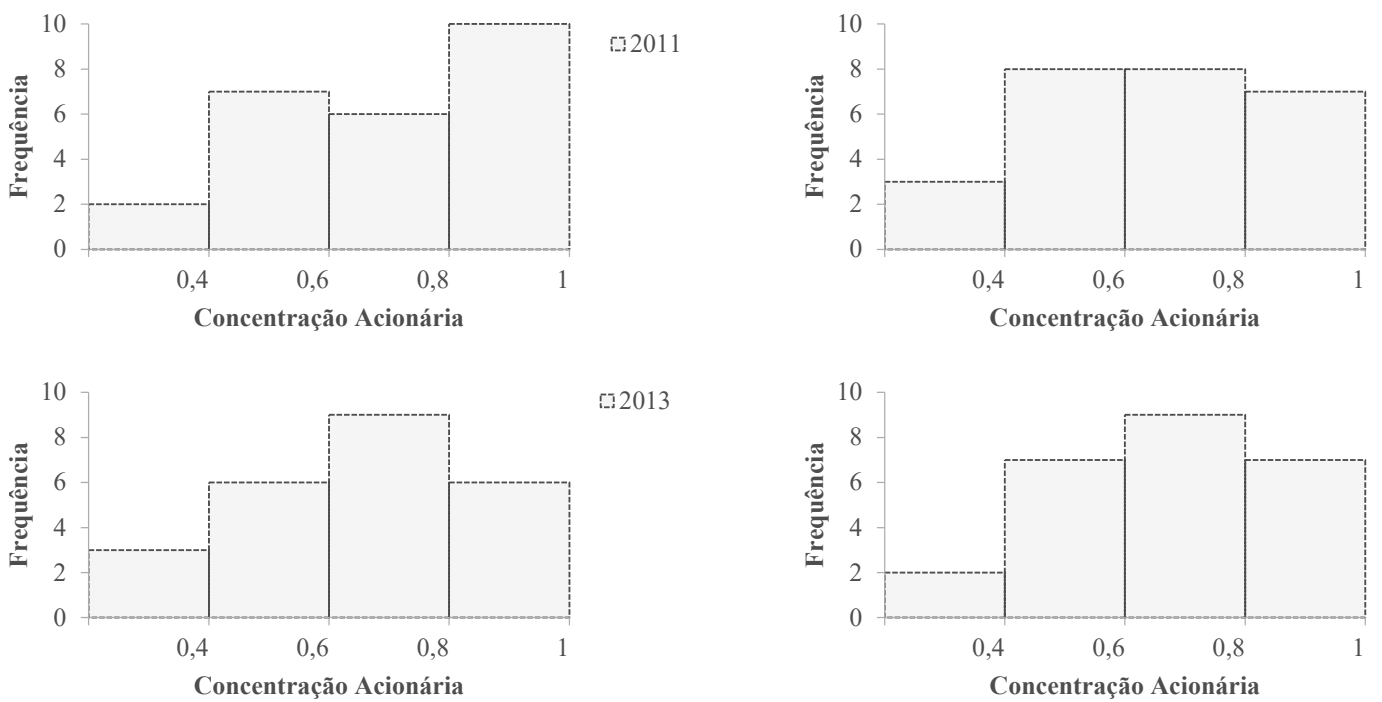

2013

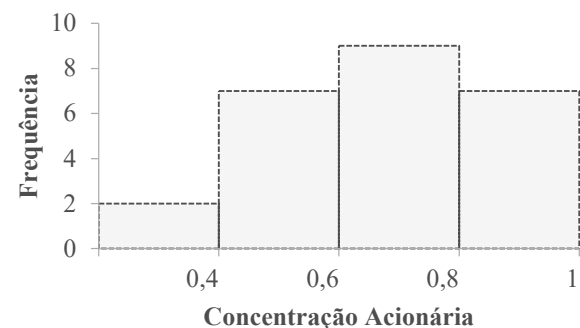

2014

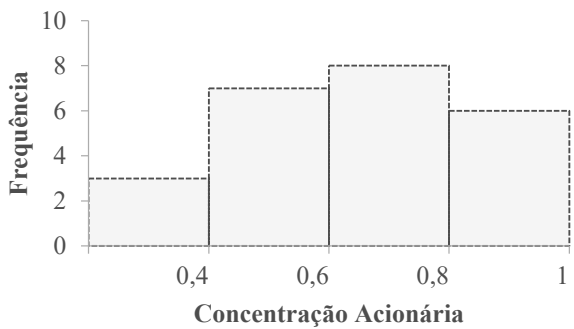

2015

Fonte: Elaborado pelos autores

\section{Apêndice B - Histogramas (por segmento - em número de empresas)}
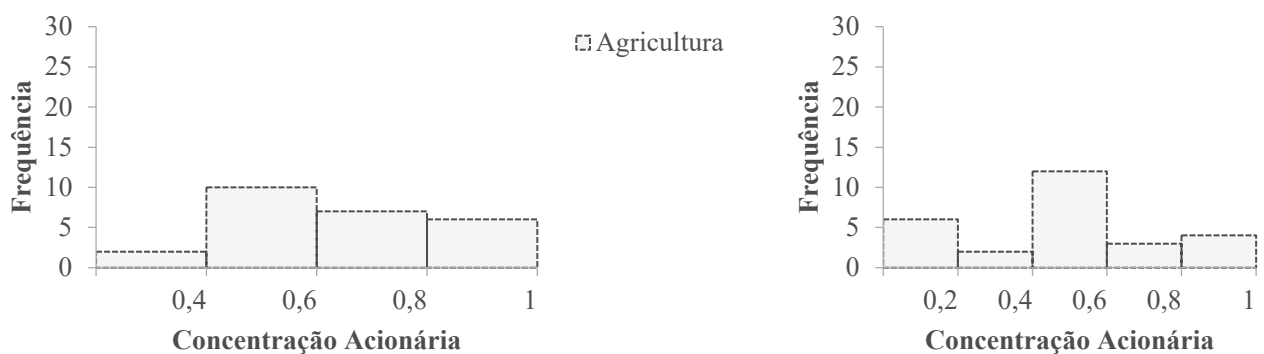

Carnes Derivados
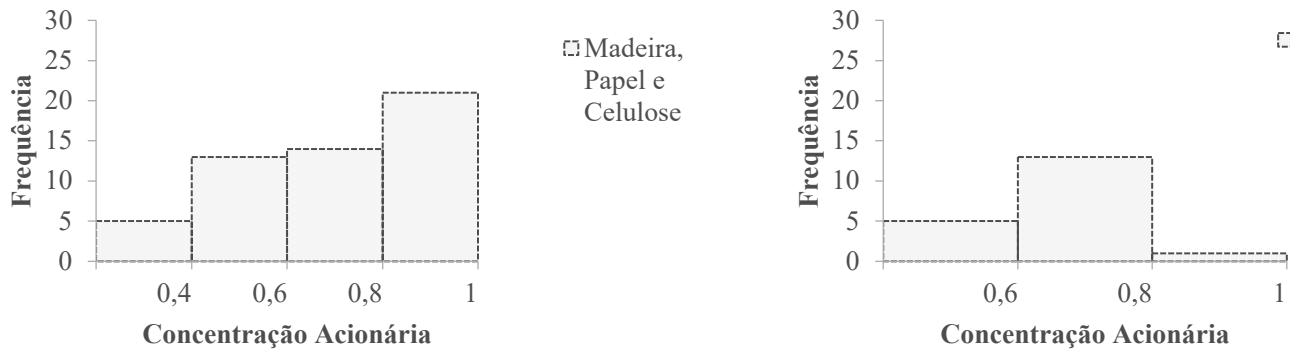

Fonte: Elaborado pelos autores 
Apêndice C - Correlação de Spearman

\begin{tabular}{|c|c|c|c|c|c|c|c|c|c|c|c|}
\hline Variáveis & (1) & (2) & (3) & (4) & (5) & (6) & (7) & (8) & (9) & (10) & (11) \\
\hline (1) Índice de Evidenciação Binário & 1 & & & & & & & & & & \\
\hline \multirow{2}{*}{ (2) Conc. Acionária } & 0,099 & 1 & & & & & & & & & \\
\hline & 0,300 & & & & & & & & & & \\
\hline \multirow{2}{*}{ (3) Rep. dos Ativos Biológicos } & 0,591 & 0,095 & 1 & & & & & & & & \\
\hline & 0,000 & 0,323 & & & & & & & & & \\
\hline \multirow{2}{*}{ (4) Rentabilidade } & $-0,079$ & 0,038 & 0,032 & 1 & & & & & & & \\
\hline & 0,413 & 0,692 & 0,743 & & & & & & & & \\
\hline \multirow{2}{*}{ (5) Endividamento } & 0,076 & $-0,083$ & $-0,076$ & $-0,313$ & 1 & & & & & & \\
\hline & 0,426 & 0,387 & 0,428 & 0,001 & & & & & & & \\
\hline \multirow{2}{*}{ (6) Porte } & 0,093 & $-0,298$ & $-0,106$ & $-0,006$ & 0,454 & 1 & & & & & \\
\hline & 0,333 & 0,002 & 0,268 & 0,953 & 0,000 & & & & & & \\
\hline \multirow{2}{*}{ (7) Liquidez Acionária } & 0,057 & $-0,372$ & $-0,143$ & 0,093 & 0,253 & 0,810 & 1 & & & & \\
\hline & 0,556 & 0,000 & 0,133 & 0,333 & 0,008 & 0,000 & & & & & \\
\hline \multirow{2}{*}{ (8) Madeira, Papel e Celulose } & 0,258 & 0,227 & 0,409 & 0,211 & $-0,161$ & 0,011 & $-0,043$ & 1 & & & \\
\hline & 0,006 & 0,017 & 0,000 & 0,026 & 0,092 & 0,911 & 0,658 & & & & \\
\hline \multirow{2}{*}{ (9) Carnes e Derivados } & $-0,483$ & $-0,068$ & $-0,554$ & $-0,163$ & 0,219 & 0,242 & 0,201 & $-0,492$ & 1 & & \\
\hline & 0,000 & 0,476 & 0,000 & 0,088 & 0,021 & 0,011 & 0,034 & 0,000 & & & \\
\hline \multirow{2}{*}{ (10) Agricultura } & $-0,050$ & $-0,200$ & 0,001 & $-0,059$ & $-0,268$ & $-0,403$ & $-0,146$ & $-0,442$ & $-0,275$ & 1 & \\
\hline & 0,606 & 0,036 & 0,988 & 0,542 & 0,005 & 0,000 & 0,126 & 0,000 & 0,004 & & \\
\hline \multirow{2}{*}{ (11) Produção Sucroalcooleira } & 0,289 & $-0,013$ & 0,093 & $-0,038$ & 0,283 & 0,159 & $-0,018$ & $-0,338$ & $-0,210$ & $-0,189$ & 1 \\
\hline & 0,002 & 0,895 & 0,331 & 0,691 & 0,003 & 0,095 & 0,853 & 0,000 & 0,027 & 0,047 & \\
\hline
\end{tabular}

Fonte: Elaborado pelos autores

Nota: O p-valor está na linha abaixo de cada variável. 


\section{Apêndice D - Gráficos de Dispersão (por ano)}

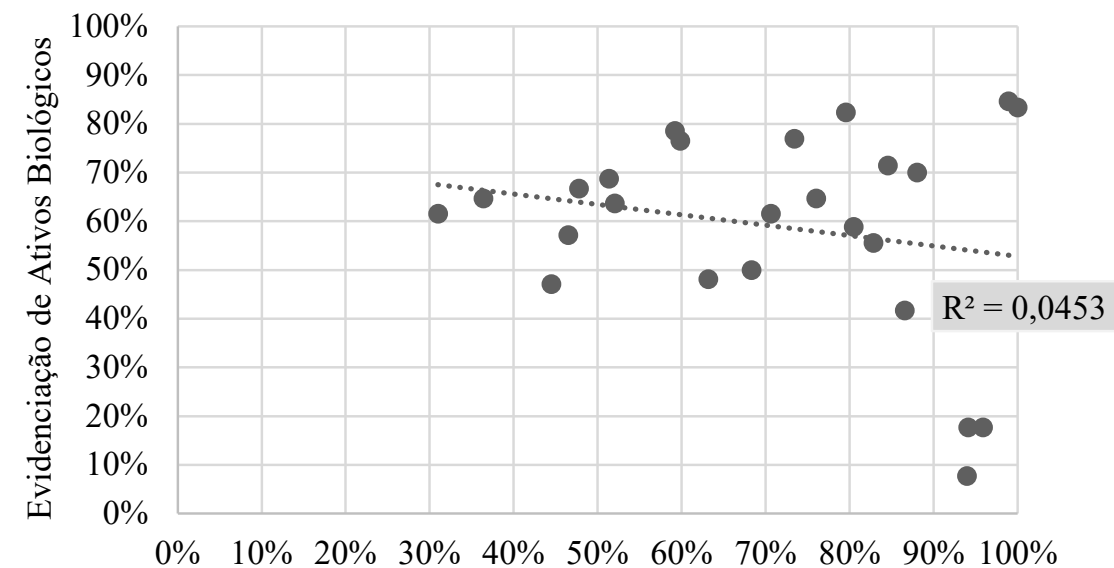

Concentração Acionária

- Índice de cada empresa em 2011

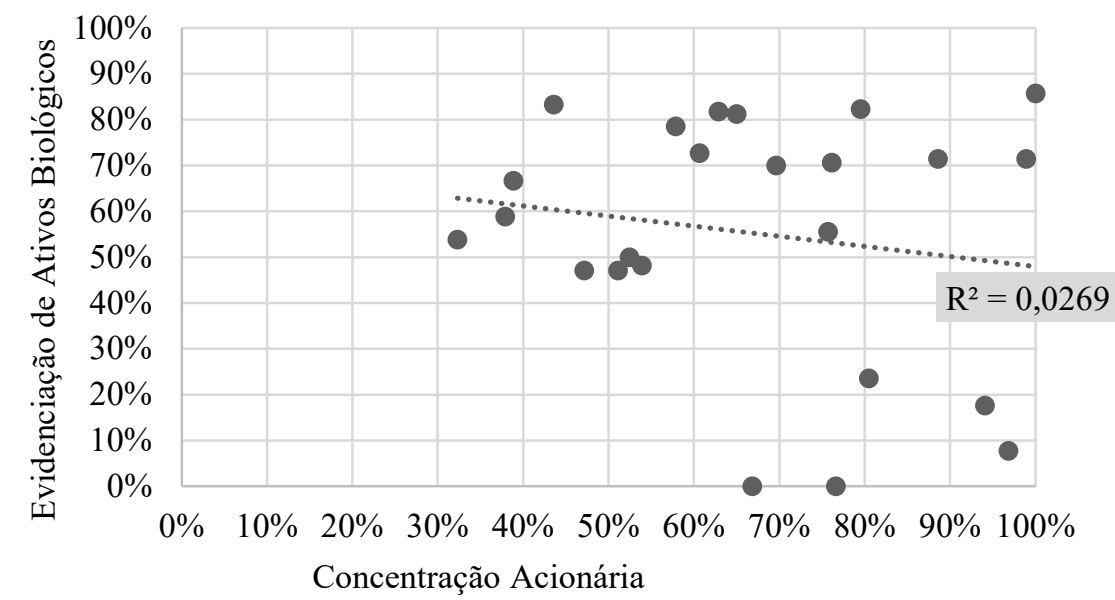

- Índice de cada empresa em 2013

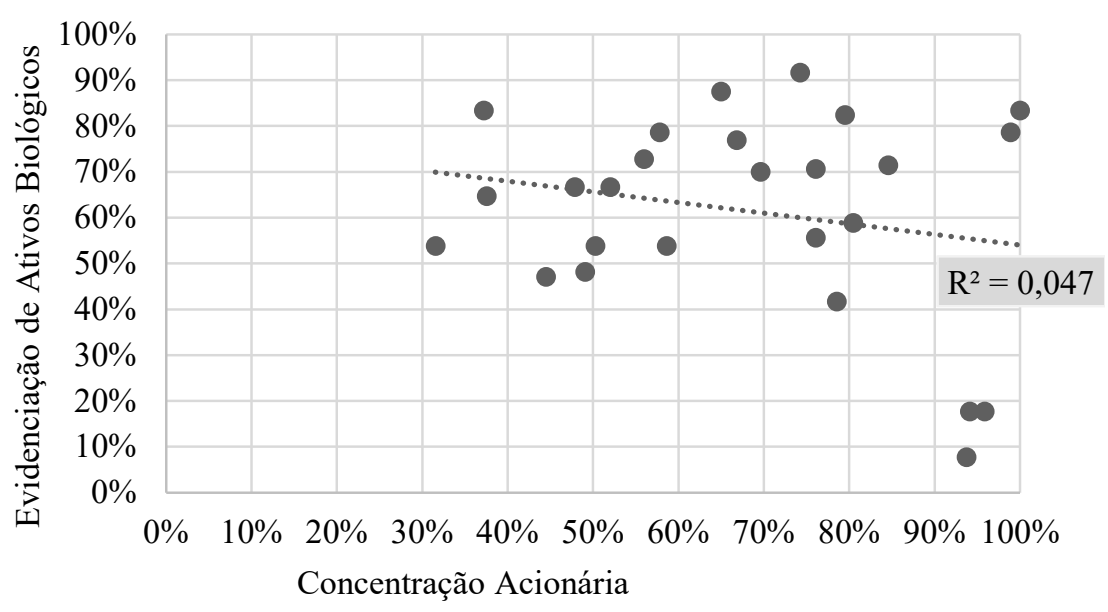

- Índice de cada empresa em 2012

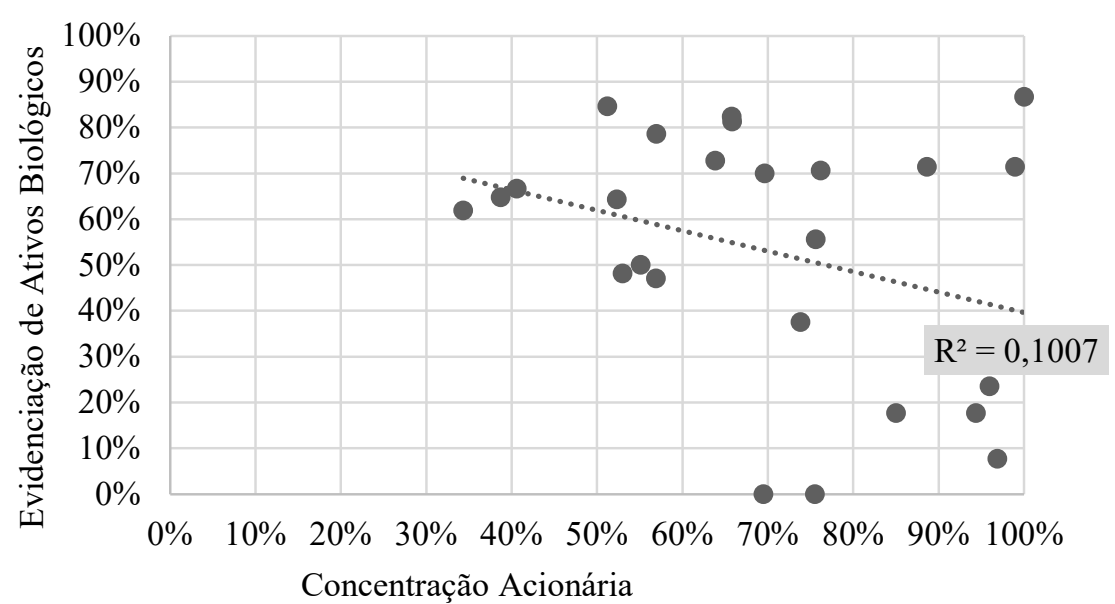

- Índice de cada empresa em 2014 
Apêndice D - Gráficos de Dispersão (por ano) - continuação

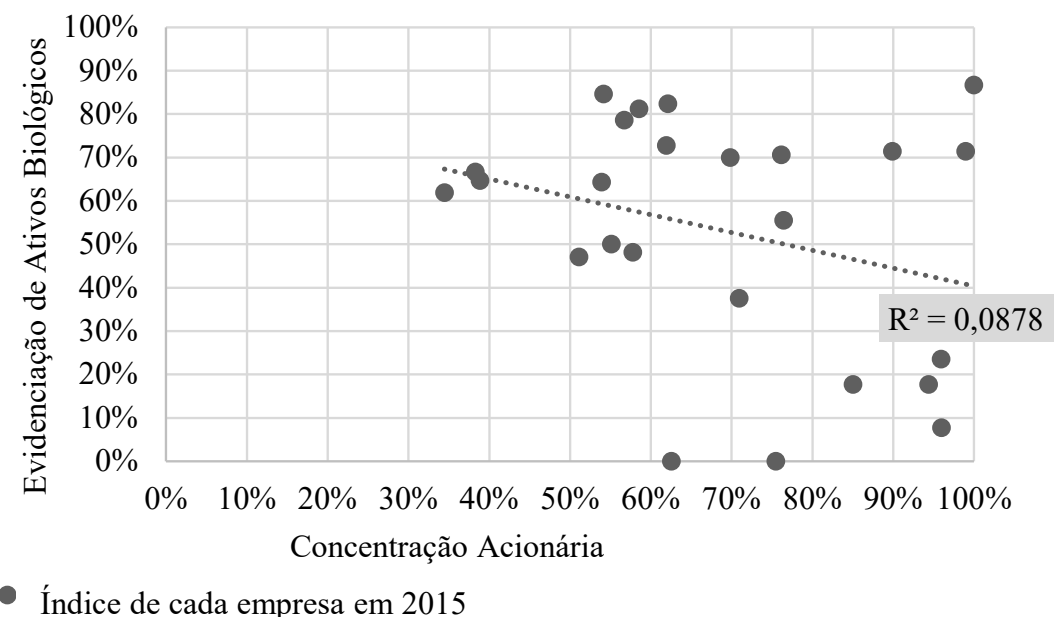

Fonte: Elaborado pelos autores 